\title{
The role of sterols in plant response to abiotic stress
}

\author{
Agata Rogowska (iD) Anna Szakiel iD
}
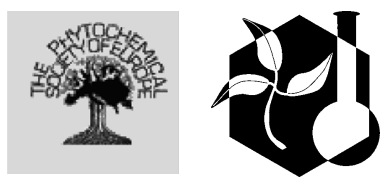

Received: 30 October 2019/Revised: 15 June 2020/ Accepted: 29 June 2020/Published online: 10 July 2020

(C) The Author(s) 2020

\begin{abstract}
Sterols are integral components of the membrane lipid bilayer and they are involved in many processes occurring in plants, ranging from regulation of growth and development to stress resistance. Maintenance of membrane homeostasis represents one of the principal functions of sterols in plant cells. Plant cell membranes are important sites of perception of environmental abiotic factors, therefore, it can be surmised that sterols may play an important role in the plant stress response. The aim of this review was to discuss the most representative trends in recent studies regarding the role of sterols in plant defense reactions to environmental factors, such as UV radiation, cold and drought stress. Some correlations were observed between changes in the sterol profile, referring to the ratios of individual compounds (including 24-methyl/ ethyl sterols and sitosterol/stigmasterol) as well as the relative proportions of conjugated sterols (ASGs, SGs and SEs) and the nature of the stress response. Diversity of sterols and their conjugated forms may allow sessile plants to adapt to environmental stress conditions.
\end{abstract}

A. Rogowska $(\square) \cdot$ A. Szakiel Department of Plant Biochemistry, Faculty of Biology, University of Warsaw, ul. Miecznikowa 1, 02-096 Warsaw, Poland e-mail: a.rogowska@biol.uw.edu.pl

A. Szakiel

e-mail: szakal@biol.uw.edu.pl
Keywords Abiotic stress - Drought - Cold acclimation $\cdot$ Phytosterols $\cdot$ Stress tolerance $\cdot$ UV radiation

$\begin{array}{ll}\text { Abbreviations } \\ \text { ASG } & \text { Acyl steryl glycoside } \\ \text { CYP710A } & \text { C22-sterol desaturase } \\ \text { FW } & \text { Fresh weight } \\ \text { HMGR } & \text { 3-Hydroxy-3-methyl-glutaryl-coenzyme } \\ & \text { A reductase } \\ \text { MEP } & \text { 2-C-methyl-d-erythritol 4-phosphate } \\ & \text { pathway } \\ \text { MVA } & \text { Mevalonic acid pathway } \\ \text { PSAT } & \text { Phospholipid: sterol acyltransferase } \\ \text { PUFA } & \text { Polyunsaturated fatty acid } \\ \text { SE } & \text { Steryl ester } \\ \text { SF } & \text { Steryl ferulate } \\ \text { SG } & \text { Steryl glycoside } \\ \text { SGT } & \text { Sterol glucosyl transferase } \\ \text { SMT1 } & \text { C24-sterol methyltransferase 1 } \\ \text { SMT2 } & \text { C24-sterol methyltransferase 2 }\end{array}$

\section{Introduction}

Sterols are natural organic compounds belonging to the isoprenoid class which have diverse and essential functions in all eukaryotes. Together with glycerolipids and sphingolipids, sterols are structural 
components of cell membranes and contribute to maintaining their permeability and fluidity (Hartmann 1998; Clouse 2002). Sterols regulate acyl chain ordering, thereby sustaining and reinforcing the domain structure of cell membranes (Schaller 2004; Dufourc 2008). Some sterols also play a role in controlling the metabolic processes associated with membranes by forming special structures with sphingolipids, referred to as microdomains (also known as nanodomains or lipid rafts). Microdomains have been shown to increase the stability and activity of embedded protein complexes, and they are believed to play an important role in processes such as channel regulation, protein trafficking, signal transduction and plant-pathogen interactions (Dufourc 2008; Tapken and Murphy 2015). Thus, in addition to their membrane architectural function, sterols also affect the activity of integral membrane proteins, including enzymes, ion channels, receptors and components of signal transduction pathways such as ATPases (Clouse 2002; Schaller 2004). Metabolic and regulatory functions of sterols involve plant growth and development, cellular proliferation and differentiation. Sterols are the biosynthetic precursors of steroid hormones in various organisms, including brassinosteroids in higher plants. Due to their crucial role as components of cell membranes and their additional functions relating to fundamental metabolic and developmental processes, these compounds are classified as "primary" (or general) metabolites in plants. They have also been identified as important precursors of specialized metabolites, such as steroidal sapogenins, steroidal glycoalkaloids or cardenolides (Hartmann 1998; Moreau et al. 2002).

Considering all the manners in which sterols contribute to the maintenance of the homeostasis of cell membranes, it can be expected that sterols play an important role in plant response to stress, particularly abiotic stress factors. Environmental conditions such as UV radiation, low/high temperatures, salinity and drought might cause dramatic alterations in the physical state and chemical composition of plant cells (Hollósy 2002; Barrero-Sicilia et al. 2017; Kumar et al. 2018). Relative proportions of constituent lipid classes determine membrane fluidity and permeability. Alterations in these proportions, as well as changes in the saturation of the fatty acid residues of phosphoand glycolipids, lead to modifications in the physical and chemical properties of the membrane (Valitova et al. 2019). Abiotic stress factors significantly influence membrane composition, since membranes act as primary sensors of temperature and maintain selective permeability of the membrane to ions and other molecules (Örvar et al. 2000; Valitova et al. 2016). It is widely understood that sterols can affect the state of the membrane, not only by changes in their total content, but also by variations in their profile, specifically the composition ratios of compounds such as sitosterol and stigmasterol (Valitova et al. 2019; Aboobucker and Suza 2019).

Plant response to abiotic stress is complex and multi-leveled, including numerous mechanisms and activating a wide range of signaling pathways. Among various environmental impacts of global climate change, the effects of abiotic stress on plant growth, development and metabolism has attracted increasing attention. The aim of this review was to provide a representative overview of recent studies concerning the role of sterols in plant defense responses to abiotic stress. Numerous previous reports concerned the functions of sterols in the model plant Arabidopsis thaliana (Clouse 2002; Schaller 2004), which remains the species of choice for many types of molecular and metabolic studies (Darnet and Schaller 2019), however, an increasing number of studies have focused on economically important crops, such as barley (Hordeum vulgare) grapevine (Vitis vinifera), oat (Avena sativa), potato (Solanum tuberosum), rice (Oryza sativa), rye (Secale cereale), tomato (Lycopersicon esculentum) and wheat (Triticum aestivum). Moreover, some abiotic stress factors, particularly those which are reproducible under experimental conditions such as UV-irradiation, have been evaluated for their ability to increase the content of sterols or their specialized derivatives, steroidal saponins, in various medicinal plants and some algae.

\section{Biosynthesis of sterols}

Plant, fungal and animal cells differ in their content and diversity of sterols, a difference which originates during post-squalene sterol biosynthesis, primarily at the cyclization step of 2,3-oxidosqualene leading to lanosterol in fungi and mammals or cycloartenol in some protists and plants (Benveniste 2004; Darnet and Schaller 2019). Fungal and mammalian cells each contain one major sterol, namely ergosterol and 


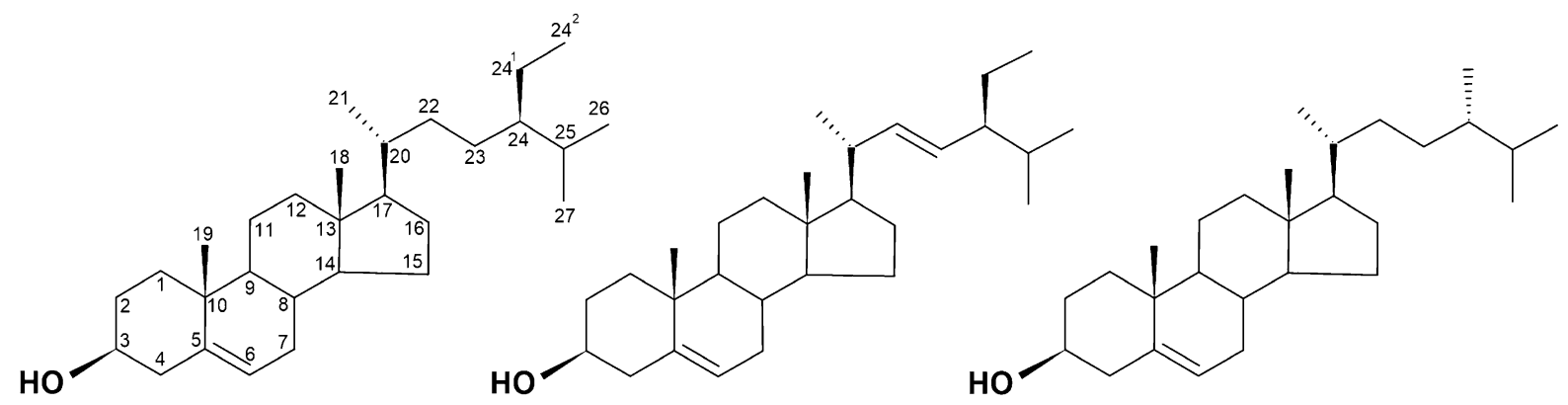

Fig. 1 Structures of the most common plant sterols, sitosterol, stigmasterol and campesterol (from left to right)

cholesterol, respectively, whereas plants synthesize a complex mixture of sterols, with sitosterol, stigmasterol and campesterol being some of the most abundant compounds (Fig. 1). However, significant levels of cholesterol can also be found in some plants, such as in representatives of the Solanaceae family. It is uncertain why plants require a mixture of sterols rather than one unique compound as found in other organisms (Hartmann 1998). Nevertheless, it is possible that the fluctuations in the sterol composition, such as changes in the ratio of campesterol to sitosterol or of sitosterol to stigmasterol, may be essential for certain processes relating to plant growth and development, as well as processes involved in stress compensation (Schaeffer et al. 2001; Aboobucker and Suza 2019). Therefore, the diversity of sterols may be related to the broad spectrum of their vital functions in plants (Valitova et al. 2016).

In addition to structural diversity of their carbon skeleton, sterols occur in plants in many forms, including steryl esters (SE), steryl glycosides (SG) and acyl steryl glycosides (ASG). The relative content and profile of conjugated sterols may vary among species and can change under different environmental conditions (Ferrer et al. 2017).

The sterol biosynthetic pathway in plants is a complex and multi-stage process, beginning with the initial step of acetate conversion to squalene, the common precursor of all sterols and triterpenoids, via the mevalonic acid pathway (MVA). This is followed by cyclization of the oxidized linear precursor $(2,3$ oxidosqualene) into cycloartenol and further transformations of this into various end products. Major enzymes involved in post-oxidosqualene cyclization of phytosterols are C24-sterol methyltransferases and C22-sterol desaturase (CYP710A). The side chain of phytosterols usually feature additional methyl or ethyl group at position C24. Two distinct isoforms of SMT enzymes (SMT1 and SMT2), localized in the endoplasmic reticulum, are involved in $\mathrm{C} 24$ primary and secondary methylation. SMT2 activity determines the ratio of 24-methyl- and 24-ethylsterols, which is crucial during plant ontogenesis and response to stress factors (Valitova et al. 2016). Secondary methylation is the final step in sterol biosynthesis and results in the formation of 24-ethylsterols like sitosterol and stigmasterol. Conversion of sitosterol into stigmasterol is catalyzed by $\mathrm{C} 22$-sterol desaturase by introduction of a double bond at C22 (Raksha et al. 2016; Valitova et al. 2016).

Thus, the biosynthetic pathway of sterols in plants passes through many branching points and can be regulated at various levels. Several of the final steps of this pathway, starting from squalene, might be crucial for plant response to stress factors. First, the cyclization of 2,3-oxidosqualene represents a very important branch point between sterols and triterpenoids, i.e. between general and specialized metabolism (Moses et al. 2013). Secondly, there are two branches from cycloartenol leading either to cholesterol or to other precursors of plant sterols (Aboobucker and Suza 2019). Downstream in the phytosterols pathway, the branch point at 24-methylenelophenol and 24-ethylidenelophenol directs metabolic flux either to campesterol and, subsequently, brassinosteroids, or to the 24-ethyl sterols, sitosterol and stigmasterol. This branch point contributes to establishment of the campesterol to sitosterol ratio (Schaller 2004). The intracellular balance of 24-methyl- and 24-ethylsterols, in addition to the ratio between sitosterol and stigmasterol, are of great physiological importance for plant growth and development, as well as for the stress response (Valitova et al. 2016). Lastly, free sterols can be converted into various sterol conjugates, 
influencing the liquid-ordered phase formation in membranes and modulating plant response to environmental stimuli (Grosjean et al. 2015).

\section{Sterol forms occurring in plants}

As previously mentioned, sterols can be found in plants in free as well as conjugated forms (Fig. 2). In all conjugated forms, the $\mathrm{C} 3$ position hydroxyl group plays a major role in distinguishing between sterol compounds: in SEs it is esterified with fatty acid, whereas in SGs it is linked with sugar through a $\beta$ glycosidic bond. ASGs are SG derivatives with fatty acids which are esterified to the C6 hydroxyl group of the sugar moiety (Ferrer et al. 2017). Steryl ferulates (SFs), found in numerous cereal grains and other seeds, are types of SEs which are esterified with ferulic acid at the C3 hydroxyl group (Mandak and Nyström 2012).

Distribution of conjugated sterols varies among organs and tissues and depends on both the ontogenesic stage of the organ and the influence of stress factors. In plant tissues like the tapetal cells of anthers, pollen grains, seeds and mature leaves, SEs are the most abundant sterol forms (Villette et al. 2015). SE accumulation has been observed when plant cell cultures reach stationary phase or during seed maturation (Bouvier-Navé et al. 2010). The length of esterified fatty acids may range from $\mathrm{C} 12$ to $\mathrm{C} 22$, with the most common compounds being palmitic, stearic, oleic, linoleic and linolenic acids (Ferrer et al. 2017). SEs can be regarded as a storage pool of sterols in plant cells that ensures an appropriate level of free sterols and is also involved in the recycling of free sterols and fatty acids released from cell membranes in senescing tissues. Enzymes involved in SE biosynthesis are sterol acyltransferases, proteins which catalyze the transfer of fatty acids to the hydroxyl group at position C3 of the sterol core (Lara et al. 2018; Bouvier-Navé et al. 2010).

Cholesterol, campesterol and sitosterol glucosides are the most abundant glycosylated sterols (SGs and ASGs) occurring in plants. The enzyme involved in SGs synthesis is UDP-glucose sterol glucosyl transferase (SGT), a protein localized in plasma membrane (Schaller 2004). Levels of glycosylated sterols differ depending on the tissue and these may change in response to developmental and environmental cues. The predominant sugar found in glycosylated sterols is glucose, but other monosaccharides such as galactose, xylose and mannose have also been reported. SGs may contain up to four sugar residues per molecule. ASGs

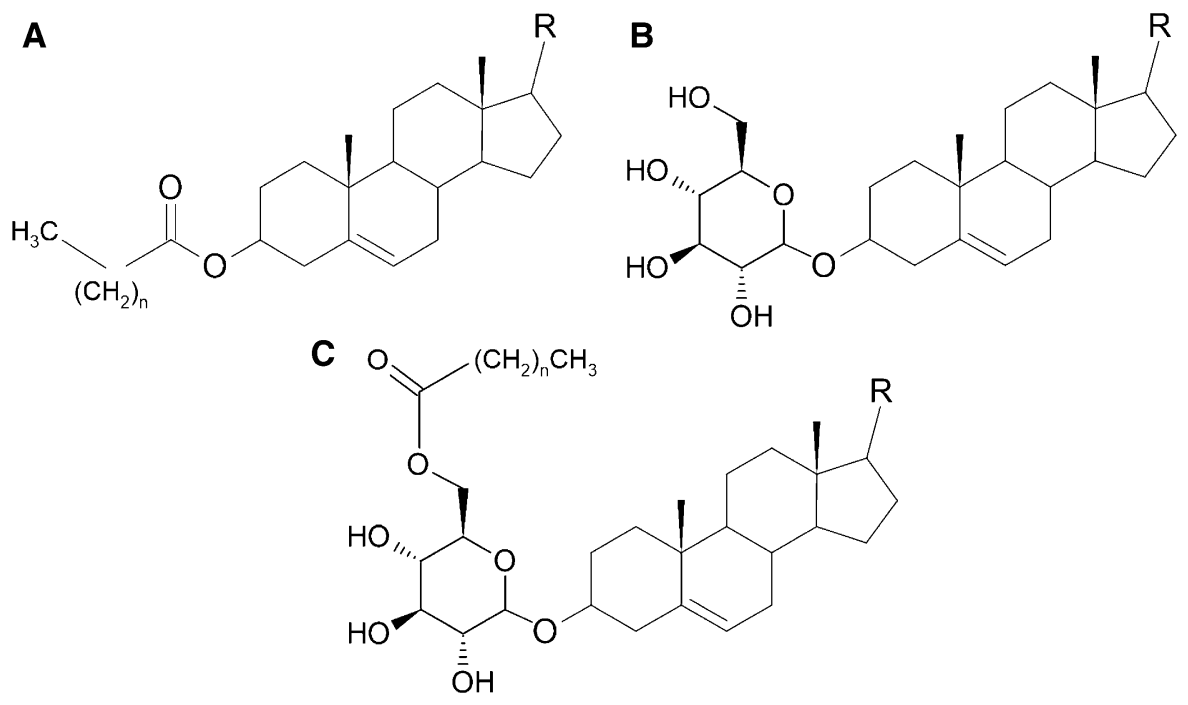

Fig. 2 Conjugated forms of sterols occurring in plants. a Steryl ester (SE), b steryl glycoside (SG), c acyl steryl glycoside (ASG). Rside chain 
usually consist of saturated and unsaturated C16 and C18 fatty acids, but unusual fatty acids can also be conjugated. SGs and ASGs are usually a minority in the total sterol fraction obtained from the most plant species. Nevertheless, plants belonging to the genus Solanum are characterized by a high content of glycosylated sterols (Ferrer et al. 2017).

\section{Impact of UV radiation on the content of sterols}

Solar ultraviolet (UV) light consists of three types of radiation with different ranges in wavelength, namely UV-A (315-400 nm), UV-B (280-315 nm) and UV-C (100-280 nm). UV-C radiation carries more energy per photon in comparison to other types, but it does not reach the Earth's surface, being absorbed by atmospheric oxygen and ozone. In contrast, the stratospheric ozone layer absorbs only a fraction of UV-B and even less of UV-A radiation. Moreover, due to the anthropogenic production of ozone depleting substances and the progressive reduction of the ozone layer, UV radiation is reaching the Earth's surface in increasing intensity. Exposure to sunlight is inevitable for photosynthetic organisms like plants, so they are particularly at risk of exposure to enhanced UV irradiation (Hollósy 2002; Matus 2016).

UV radiation is harmful to most living organisms. In plants, apart from damaging DNA and proteins, it is destructive to membrane lipids and the photosynthetic apparatus, eventually leading to tissue necrosis. Plants respond to this damage through induction of a complex antioxidant defense system involving various enzymes, specialized metabolites and the accumulation of various compounds that absorb excessive UV radiation (Brosché and Strid 2003; Lake et al. 2009; Zlatev et al. 2012; Robson et al. 2015; Matus 2016). As sterols are an integral part of the cell membrane and maintain their fluidity and permeability, it is possible that these compounds also play a role in repairing the damage caused by UV radiation (Ahmed and Schenk 2017).

A high value crop which is potentially exposed to enhanced UV-B radiation is grapevine (Vitis vinifera). $V$. vinifera is one of the most extensively cultivated fruit crops in the world, well-adapted to UV radiation and can, therefore, serve as a suitable model for the study of plant UV stress responses and adaptation (Matus 2016). The effect of a "field-simulating" dose of UV-B radiation $\left(4.75 \mathrm{~kJ} \mathrm{~m}^{-2}\right.$ per day), administrated at low- and high-fluence rates to grapevine leaf tissues, was investigated (Gil et al. 2012). Low intensity UV-B treatment ( $16 \mathrm{~h}$ at $8.25 \mu \mathrm{W} \mathrm{cm}{ }^{-2}$ ) resulted in increased levels of sitosterol and stigmasterol, especially in young leaves. The concentration of sitosterol, the most abundant sterol in grapevine, increased 16.4-fold in young leaves and eightfold in mature leaves after low UV-B treatment. After high intensity UV-B radiation ( $4 \mathrm{~h}$ at $33 \mu \mathrm{W} \mathrm{cm}{ }^{-2}$ ), the levels of this compound increased much less significantly (4.8-fold in young leaves and 1.8-fold in mature leaves). The concentration of stigmasterol increased 3.2-fold and 2.3-fold (exclusively in young leaves) upon low and high intensity UV-B radiation, respectively. Thus, the biosynthesis and accumulation of sitosterol and stigmasterol was stimulated most potently by low intensity UV-B. In turn, high intensity UV-B induced accumulation of other compounds with antioxidant properties, including mono- and diterpenes, tocopherol and phytol. These results might suggest that low intensity UV-B radiation applied to grapevine leaves induces acclimation responses including synthesis of sterols, compounds related with membrane stability, while higher intensity radiation activates defensive mechanisms counteracting oxidative damage. Low intensity UV-B appears to induce the synthesis of enzymes of the terpene cytosolic mevalonic acid (MVA) pathway leading to increased production of sterols and triterpenoids (such as lupeol, occurring in grapevine leaves) involved in stress adaptation, whereas high intensity UV-B radiation promotes the production of plastidic terpenes via the methylerytritol phosphate (MEP) pathway so as to cope with increased levels of reactive oxygen species (ROS) (Gil et al. 2012).

In contrast to what has been observed in grapevine, excessive UV-B radiation did not influence biosynthesis and accumulation of sterols in the leaves of olive (Olea europaea). O. europaea is one of the most important crops cultivated in Mediterranean regions, where UV-B radiation level is generally high. The application of low $\left(6.5 \mathrm{~kJ} \mathrm{~m}^{-2} \mathrm{day}^{-1}\right)$ and high $\left(12.4 \mathrm{~kJ} \mathrm{~m}^{-2}\right.$ day $^{-1}$ ) doses of UV-B radiation did not increase the content of sterols (represented by sitosterol) in olive leaves, however, increased accumulation of triterpenoids, ursolic acid and lupeol was observed. The increase in levels of triterpenoids (particularly ursolic acid) as well as long-chain 
alkanes could indicate that exposure of olive leaves to UV-B radiation may result in strengthening and thickening of cuticle, notably the leaf surface layer of cuticular waxes (Dias et al. 2018).

Based on the increased production of sterols and sterol derivatives in response to UV-induced stress, the application of UV irradiation as an elicitor of these metabolites has been explored with the aim of improving the quality of medicinal plants. One such study involved Withania somnifera, an indigenous medicinal plant occurring in northern India, which is used to treat neurological disorders. The medicinal properties of $W$. somnifera are primarily attributed to alkaloids and withanolides (steroidal lactones). The effects of supplemental UV-B $\left(3.6 \mathrm{~kJ} \mathrm{~m}^{-2}\right.$ day $^{-1}$ above ambient) radiation on the metabolite profile and free radical scavenging activity observed in $W$. somnifera leaves and roots were investigated under otherwise normal field conditions. Increased levels of stigmasterol and steroidal lactone withaferin A (183\% and $155 \%$, respectively, as compared with the control) were detected in UV-B-treated leaves, while the levels of campesterol, crinosterol and cholesterol significantly decreased to $48 \%, 44 \%$ and $21 \%$, respectively, as compared with the control). Stigmasterol acetate was detected in leaves only after UV-B treatment. In roots, the level of cholesterol decreased to $21 \%$ after the exposure of plants to UV-B radiation, whereas two steryl esters, stigmasterol acetate and sitosterol oleate, appeared after treatment. As in the case of grapevine, UV-B irradiation stimulated the synthesis of various compounds with antioxidant properties, such as eugenol, $\beta$-carotene, lycopene and tocopherol in $W$. somnifera leaves. The results obtained in this study suggest profound alterations in sterol composition as a result of redirections in sterol biosynthesis induced by UV-B treatment, as well as a considerable increase in levels of steryl esters (Takshak and Agrawal 2015).

Similar studies were performed on another medicinal plant, Achyranthes bidentata native to China. This plant, applied as anti-inflammatory and antibacterial agent, is rich in triterpenoid saponins (glycosides of oleanolic acid) and a steroidal derivative, ecdysterone (Li et al. 2018). A. bidentata plants were exposed to UV-B radiation for different durations and doses: $1 \mathrm{~h}$ $\left(0.74 \mathrm{~kJ} \mathrm{~m}^{-2}\right), 2 \mathrm{~h}\left(1.48 \mathrm{~kJ} \mathrm{~m}^{-2}\right), 3 \mathrm{~h}\left(2.21 \mathrm{~kJ} \mathrm{~m}^{-2}\right)$ and $4 \mathrm{~h}\left(2.95 \mathrm{~kJ} \mathrm{~m}^{-2}\right)$. The content of ecdysterone increased 2.5-fold in leaves and 3.5-fold in roots after $2 \mathrm{~h}$ UV-B exposure. In turn, the highest content of oleanolic acid was observed after $3 \mathrm{~h}$ of UV-B treatment, with a twofold increase detected in the leaves and 3.2-fold in the roots. It was demonstrated that after UV-B exposure the expression levels of several genes involved in terpene/sterol biosynthesis pathway were upregulated, including squalene synthase $(S S)$, squalene epoxidase $(S E), \beta$-amyrin synthase $(\beta-A S)$ and cycloartenol synthase $(C A S)$. Thus, the expression levels of key enzyme genes of both post-squalene parallel branches of biosynthetic pathways leading to sterols and triterpenoids were found to be simultaneously induced (Li et al. 2018).

Although potentially more harmful than UV-B, UV-C radiation has also been used as an abiotic elicitor to increase the production of sterols in algae (Ahmed and Schenk 2017). In the last few decades, after the discovery that phytosterols can reduce the intestinal absorption of cholesterol and thus help maintain cardiovascular health, these compounds have become valuable to the biotechnological industry especially with regard to production of various food additives. Microalgae present a source of phytosterols because these organisms can easily adapt to varying environmental conditions and are relatively easy to cultivate, even in wastewater, meaning that competition with other food production can be eliminated. The haptophyte microalgae Pavlova lutheri produces relatively high quantities of sterols (up to $5.1 \% \mathrm{DW}$ ). UV-C irradiation applied at $100 \mathrm{~mJ} \mathrm{~cm}^{-2}$ doubled the total bioaccumulation of sterols in P. lutheri. Among nineteen sterol compounds identified in $P$. lutheri, the content of only six compounds (poriferasterol, epicampesterol, methylergostenol, fungisterol, dihydrochondrillasterol and chondrillasterol) increased after elicitation with UV-C irradiation. In unirradiated samples, the levels of fungisterol and chondrillasterol were undetectable, while in irradiated samples the quantities of those compounds increased considerably. These observations may suggest that fungisterol and chondrillasterol are more active in membrane repair processes than other sterols (Ahmed and Schenk 2017).

The effects of UV radiation on the synthesis and metabolism of sterols observed in the reviewed plant studies are presented in Table 1 . The most ubiquitous response to stress induced by UV irradiation is the increase in synthesis and accumulation of sterols, often accompanied by alterations in sterol composition and sometimes by increased formation of 
Table 1 Changes in sterol content in plants and algae exposed to UV radiation stress

\begin{tabular}{|c|c|c|c|c|}
\hline Species & Main sterol profile & $\begin{array}{l}\text { Stress } \\
\text { factor }\end{array}$ & Effect & References \\
\hline $\begin{array}{l}\text { Grapevine } \\
\text { Vitis } \\
\text { vinifera }\end{array}$ & Sitosterol, stigmasterol & $\begin{array}{l}\text { UV-B } \\
\text { radiation } \\
\text { (low } \\
\text { intensity) }\end{array}$ & $\begin{array}{l}\text { Increased levels of sitosterol (16.4-fold in } \\
\text { young leaves, eightfold in mature leaves) } \\
\text { and stigmasterol ( } 3.2 \text {-fold in young } \\
\text { leaves); induction of terpene synthase } \\
\text { activity (eightfold in young leaves, } \\
\text { threefold in mature leaves) }\end{array}$ & $\begin{array}{l}\text { Gil et al. } \\
\text { (2012) }\end{array}$ \\
\hline $\begin{array}{r}\text { Olive Olea } \\
\text { europaea }\end{array}$ & Sitosterol & $\begin{array}{l}\mathrm{UV}-\mathrm{B} \\
\text { radiation }\end{array}$ & No significant influence on sterol content & $\begin{array}{l}\text { Dias et al. } \\
\text { (2018) }\end{array}$ \\
\hline $\begin{array}{l}\text { Withania } \\
\text { somnifera }\end{array}$ & $\begin{array}{l}\text { Stigmasterol, campesterol, crinosterol, } \\
\text { cholesterol; steroidal lactone withaferin A }\end{array}$ & $\begin{array}{l}\mathrm{UV}-\mathrm{B} \\
\text { radiation }\end{array}$ & $\begin{array}{l}\text { Increased levels of stigmasterol }(183 \%) \text { and } \\
\text { withaferin A }(155 \%) \text {, decreased levels of } \\
\text { campesterol, crinosterol and cholesterol in } \\
\text { leaves; increased levels of SEs in roots }\end{array}$ & $\begin{array}{l}\text { Takshak } \\
\text { and } \\
\text { Agrawal } \\
(2015)\end{array}$ \\
\hline $\begin{array}{l}\text { Achyranthes } \\
\text { bidentata }\end{array}$ & $\begin{array}{l}\text { Steroidal derivative ecdysterone (other } \\
\text { sterols not identified) }\end{array}$ & $\begin{array}{l}\text { UV-B } \\
\text { radiation }\end{array}$ & $\begin{array}{l}\text { Increased content of ecdysterone ( } 2.5 \text {-fold } \\
\text { in leaves and } 3.5 \text {-fold in roots); increased } \\
\text { expression levels of genes of key enzymes } \\
\text { involved in sterol biosynthesis pathway }\end{array}$ & $\begin{array}{l}\text { Li et al. } \\
(2018)\end{array}$ \\
\hline $\begin{array}{l}\text { Algae } \\
\text { Pavlova } \\
\text { lutheri }\end{array}$ & $\begin{array}{l}\text { Nineteen sterols identified (including } \\
\text { clionasterol, } 4 \alpha \text {-methylporiferast- } 22- \\
\text { enol, poriferasterol, methylpavlovol, } \\
\text { epicampesterol) }\end{array}$ & $\begin{array}{l}\mathrm{UV}-\mathrm{C} \\
\text { radiation }\end{array}$ & $\begin{array}{l}\text { Twofold increase in total sterol content; } \\
\text { alterations in sterol profile (increased } \\
\text { levels of fungisterol and chondrillasterol } \\
\text { undetectable before UV-C treatment) }\end{array}$ & $\begin{array}{l}\text { Ahmed } \\
\text { and } \\
\text { Schenk } \\
(2017)\end{array}$ \\
\hline
\end{tabular}

conjugated steryl forms, particularly esters. The increase in sterol biosynthesis seems to be more pronounced in response to lower doses of UV irradiation, whereas at higher doses the production of various ROS scavengers is a priority. However, this observed pattern cannot be generalized to all species, as some plants, such as the olive tree, exhibit no change in terms of sterol biosynthesis. Thus, in some plants, alternative mechanisms of response to stress induced by UV radiation may be more prevalent, for instance those based on strengthening the protective barriers (such as cuticular waxes) or accumulation of pigments which absorb excessive UV irradiation.

\section{Sterols in cold stress}

Cold stress in plants has an immense impact on their phenotype and metabolism. Exposure to low temperature suppress growth and development of the plant, cause alterations in cell membrane composition as well as changes in cell metabolism. Plants have needed to evolve to adapt to cold stress, not least due to the natural occurrence of periodic seasonal changes in temperature. Currently, increases in the frequency, severity and duration of temperature extremes are anticipated to be a frequent feature of the weather. Climate changes have resulted in even greater temperature fluctuations, including frequent periods of cold temperatures (Barrero-Sicilia et al. 2017).

The process by which plants adapt to low temperatures is known as cold acclimation. Non-acclimated rye is killed by temperatures as low as $-5{ }^{\circ} \mathrm{C}$, but after an appropriate acclimation period it can survive freezing down to $-30{ }^{\circ} \mathrm{C}$ (Thomashow 1999). Plant acclimation to cold stress is a complex and systemic process, involving a multi-level regulatory network. Changes in cells are observed on transcriptomic, proteomic and metabolic levels (Barrero-Gil and Salinas 2013; Barrero-Sicilia et al. 2017; Degenkolbe et al. 2012).

Cell membranes are important sites of cold perception and simultaneously they are the most susceptible to cold injury. Therefore, membrane stabilization against freezing damage is crucial in cold acclimation (Thomashow 1999). The primary changes in plasma membrane composition are related to the maintenance of metabolite homeostasis and involve mostly proteins and lipids. This mechanism also serves as a "temperature sensor" for the cell (Barrero-Sicilia et al. 2017). 
Fluidity of the membrane is determined by the proportion of unsaturated and saturated fatty acid, as well as other components of the membrane, including sterols. During exposure to low temperatures, the level of unsaturated lipids in cell membranes increases and this is when the transition of the membrane from fluid state to rigid gel form occurs. This process allows the cells to mechanically adapt to freezing (BarreroSicilia et al. 2017; Chen and Thelen 2013).

The ability of plants to respond to cold stress, of great importance to agriculture, has been the subject of numerous studies, and the alterations in sterol content in plants exposed to cold acclimation treatment had been intently observed (Palta et al. 1993; Whitaker 1993). The effect of cold acclimation on plasma membrane lipids was investigated in two Solanum species, a freezing-tolerant, cold-acclimating wild potato species (S. commersonii) and a freezing-sensitive, non-acclimating cultivated species ( $S$. tuberosum). Following cold acclimation treatment, several characteristic changes were observed in both species. These included an increase in unsaturated to saturated fatty acid ratio, an enhancement of the content of free sterols, particularly sitosterol, and a slight decrease in cerebrosides. In turn, a decrease in sterol to phospholipid ratio and an increase in ASGs to SGs ratio were detected only in the acclimating species, whereas they were either absent or inverted in the non-acclimating species. It was concluded that there is a correlation between a decrease in sterol to phospholipid ratio and an increase in freezing tolerance following cold acclimation. The results also suggested that a lower sterol-to-phospholipid ratio could be associated with higher membrane fluidity, and that SGs and ASGs could alter lipid bilayer fluidity through less orderly packing in the bilayer as compared with free sterols. Moreover, after acclimation treatment, both species exhibited a reduction in the proportion of cholesterol content in ASG, SG and free sterol fractions, as well as an increase in the proportions of free sitosterol and isofucosterol (Palta et al. 1993). In another plant belonging to Solanaceae family, tomato (Lycopersicon esculentum), cold-induced changes in sterol profile were observed. L. esculentum mature-green fruit was stored at chilling $\left(2^{\circ} \mathrm{C}\right)$ or non-chilling temperature $\left(15^{\circ} \mathrm{C}\right)$ for either 4 or 12 days. The content of free sterols increased more as a result of storage at $2{ }^{\circ} \mathrm{C}$ than at $15{ }^{\circ} \mathrm{C}$ in membranes from pericarp tissue, whereas the ratio of stigmasterol to sitosterol increased more at $15{ }^{\circ} \mathrm{C}$ than at $2{ }^{\circ} \mathrm{C}$ (Whitaker 1993).

Compositional changes of plasma membrane and detergent resistant membrane fractions (representing microdomains) in leaves of low-freezing tolerant oat (Avena sativa) and highly freezing tolerant rye (Secale cereale) during cold acclimation were investigated by Takahashi et al. (2016). In both species, detergent resistant membrane fractions (microdomains) contained higher proportions of sterols, sphingolipids and saturated phospholipids than were found in the plasma membrane. Three sterol classes, comprising free sterols, ASGs and SGs, were found in plasma membrane and microdomains, however, ASGs were the predominant sterol found in the microdomains of oat, while microdomains of rye contained free sterols as the major fraction. During cold acclimation the compositions of these structures differed between the two species. The total sterol content, as well as the fraction of free sterols, were reduced in plasma membrane and microdomains of A. sativa. In $S$. cereale, only the level of ASGs were reduced in both plasma membrane and microdomains. Despite the observed differences between these two species, the findings indicate that cold acclimation induces changes in the thermodynamic properties and physiological functions of microdomains. The change in proportions of sterol forms (free sterols, ASGs and SGs) may result in variable membrane behavior under freeze-induced dehydration, and thus ultimately influence plant freezing tolerance. Differences in sterol composition in microdomains may also affect the activity of some microdomain-associated proteins, particularly $\mathrm{H}^{+}$-ATPase, which is up-regulated by cold and may be involved in the regulation of intracellular $\mathrm{pH}$ and membrane potential. The results obtained in this study also suggested the importance of glycosylated forms of sterols, such as ASGs, in plant cell defense mechanisms against freeze-induced dehydration (Takahashi et al. 2016).

The recent work of Valitova et al. (2019) investigated the role of sterols in plant acclimation to low positive temperature $\left(+4{ }^{\circ} \mathrm{C}\right)$ stress in the roots and leaves of wheat (Triticum aestivum) seedlings. The results demonstrated that cold treatment causes marked changes in the ratios between 24-methyl/ethyl sterols, phospholipids and glycoceramides. Short-term $(1 \mathrm{~h})$ cold treatment increased the total sterol content in both roots and leaves, however, after $12 \mathrm{~h}$ of 
exposure to cold the total sterol content returned to control levels. The increase in free sterol levels by $13-16 \%$ was also reported in other studies on cold acclimation of wheat seedlings during 3 weeks at $+2{ }^{\circ} \mathrm{C}$ (Bohn et al. 2007). The decline in sterols by $12 \mathrm{~h}$, as was observed in T. aestivum, may be the result of modifications of free sterols, such as acylation and glycosylation, which have been shown to occur during cold acclimation in rye and oat (Takahashi et al. 2016). In the roots of cold-treated wheat seedlings, a slight increase in the ratio of 24-methyl/ethyl sterols resulted from an increase in campesterol content. In contrast, in the leaves of cold-treated seedlings, the ratio of 24-methyl/ethyl sterols was reduced due to an increase in the amounts of sitosterol and stigmasterol. Based on these data, the roots of wheat appeared to be more sensitive to cold than the leaves (Valitova et al. 2019).

The role of glycosylated forms of sterols in cold stress was confirmed in a study involving Arabidopsis mutants (Mishra et al. 2015). As previously mentioned, the proportions of SGs and ASGs are significantly altered during cold stress. That makes sterol glycosyltransferases a promising subject of research concerning the role of sterols in cold acclimation. In plants, sterol glycosyltransferases catalyze the transfer of carbohydrate molecules to sterol core, which results in SGs and ASGs synthesis. The role of TTG15/ UGT80B1 gene of Arabidopsis thaliana encoding sterol glycosyltransferase was investigated during cold stress. T-DNA insertional sgt knockout mutants with significantly reduced SGs and ASGs levels, wildtype Col-0 and p35S:TTG15/UGT80B1 restored lines were used in the experiments. The p35S:TTG15/ UGT80B1 restored lines were found to be better adapted to cold stress than TTG15/UGT80B1 knockout mutants during cold acclimated conditions. Cold acclimated conditions increased quantity of free sitosterol and sitosterol glycoside in Col-0 and p35S:TTG15/UGT80B1 restored lines, while the quantity of those compounds in TTG15/UGT80B1 knockout mutants decreased. Moreover, TTG15/ UGT80B1 gene expression was induced during freeze conditions and appeared essential for survival of plants in those conditions (Mishra et al. 2015).

The predominant cold stress induced changes in sterol content presented in this review are summarized in Table 2. Since the earlier symptoms of cold stress include changes in membrane fluidity and the phase transition of the membranes is determined by the relative proportions of constituent lipids, it can be expected that the content of sterols would be significantly altered in cold acclimation. The role of sterols

Table 2 Changes in sterol content in plants exposed to cold stress

\begin{tabular}{|c|c|c|c|c|}
\hline Plant & $\begin{array}{l}\text { Main sterol } \\
\text { profile }\end{array}$ & Stress factor & Effect & References \\
\hline $\begin{array}{l}\text { Potato Solanum commersonii } \\
\text { (freezing-tolerant) and } \\
\text { Solanum tuberosum } \\
\text { (freezing-sensitive) }\end{array}$ & $\begin{array}{l}\text { Sitosterol, } \\
\text { stigmasterol, } \\
\text { cholesterol, } \\
\text { campesterol }\end{array}$ & $\begin{array}{l}\text { Cold acclimation, } \\
10 \text { days at } \\
\text { temperature } \\
4^{\circ} / 2{ }^{\circ} \mathrm{C} \text { day/night }\end{array}$ & $\begin{array}{l}\text { Increased sterol content and alteration in } \\
\text { sterol profile in both species; a decrease in } \\
\text { sterol to phospholipid ratio and an } \\
\text { increase in ASGs to SGs ratio in } S \text {. } \\
\text { commersonii }\end{array}$ & $\begin{array}{l}\text { Palta et al. } \\
\text { (1993) }\end{array}$ \\
\hline $\begin{array}{l}\text { Tomato Lycopersicon } \\
\text { esculentum (mature-green } \\
\text { fruit) }\end{array}$ & $\begin{array}{l}\text { Sitosterol, } \\
\text { stigmasterol }\end{array}$ & $\begin{array}{l}2{ }^{\circ} \mathrm{C} \text { for } 4 \text { or } 12 \\
\text { days }\end{array}$ & $\begin{array}{l}\text { Increased free sterol content; increased ratio } \\
\text { of stigmasterol to sitosterol }\end{array}$ & $\begin{array}{l}\text { Whitaker } \\
\text { (1993) }\end{array}$ \\
\hline $\begin{array}{l}\text { Oat Avena sativa (freezing- } \\
\text { tolerant) }\end{array}$ & $\begin{array}{l}\text { Sitosterol, } \\
\text { stigmasterol, } \\
\text { cholesterol }\end{array}$ & $2{ }^{\circ} \mathrm{C}$ for 4 weeks & $\begin{array}{l}\text { Changes in proportions of sterol forms (free } \\
\text { sterols, ASGs and SGs); increased ASG } \\
\text { content (from } 68.2 \text { to } 71.7 \% \text { ) }\end{array}$ & $\begin{array}{l}\text { Takahashi } \\
\text { et al. } \\
\text { (2016) }\end{array}$ \\
\hline $\begin{array}{l}\text { Rye Secale cereale (freezing- } \\
\text { sensitive) }\end{array}$ & $\begin{array}{l}\text { Sitosterol, } \\
\text { campesterol }\end{array}$ & $2{ }^{\circ} \mathrm{C}$ for 4 weeks & Decreased ASG content (from 14.7 to $7.7 \%$ ) & $\begin{array}{l}\text { Takahashi } \\
\text { et al. } \\
\text { (2016) }\end{array}$ \\
\hline Wheat Triticum aestivum & $\begin{array}{l}\text { Sitosterol, } \\
\text { stigmasterol, } \\
\text { campesterol, } \\
\text { cholesterol }\end{array}$ & $4{ }^{\circ} \mathrm{C}$ for $1 \mathrm{~h}$ or $12 \mathrm{~h}$ & $\begin{array}{l}\text { Increased total sterol content after short- } \\
\text { term }(1 \mathrm{~h}) \text { cold treatment }(4.2 \text {-fold in } \\
\text { leaves, threefold in roots); increased } \\
\text { 24-methyl/ethyl sterol ratio in roots due to } \\
\text { 3.4-fold enhancement of campesterol } \\
\text { content }\end{array}$ & $\begin{array}{l}\text { Valitova } \\
\text { et al. } \\
\text { (2019) }\end{array}$ \\
\hline
\end{tabular}


in the plant adaptation to temperature is well documented. It has been suggested that the ability of plants to synthesize the 24-ethyl sterols, sitosterol and stigmasterol, may be a part of an evolutionary adaptation to stresses and maintenance of important membrane-associated metabolic processes (Dufourc 2008; Aboobucker and Suza 2019). The additional ethyl group branched on the alkyl chain of sitosterol and stigmasterol may reinforce van der Waals interactions with the alkyl chains of sphingolipids and phospholipids, leading to greater membrane cohesion and a lower temperature sensitivity. It also appears that the presence of membrane microdomains, with strictly regulated composition of sterols, can extend the temperature range in which membrane-associated processes can function properly (Dufourc 2008). The role of glycosylated forms of sterols, like SGs and ASGs, in defense mechanisms against cold stress was also demonstrated. The glycosylation of sterols significantly alters the biophysical properties of the membranes, indicating that the proportion of glycosylated versus free and acylated sterols may play a very important role in adaptation against adverse temperature conditions (Mishra et al. 2015).

\section{Effect of drought stress on sterol content in plants}

Many valuable crop plants are frequently exposed to drought stress, which is highly detrimental to the agricultural industry and has been an increasing problem in recent years due to global climate changes. Drought stress causes the destruction of cell membranes by disintegration of membrane lipids. Plants respond to drought stress by means of various physiobiochemical and molecular changes at cellular and molecular levels.

The role of sterols in response to drought stress due to water deprivation was investigated in seedlings of two rice (Oryza sativa) cultivars, one drought tolerant (cultivar N22) and one drought susceptible (cultivar IR64) (Kumar et al. 2015, 2018). The drought tolerant cultivar exhibited a higher content of sterols and their corresponding steryl esters and this content increased approximately twofold in plants exposed to drought stress. This increase in sterols levels and their esters was proportional to the duration of dehydration stress. Levels of the major phytosterol, sitosterol, in drought tolerant rice seedlings increased gradually from 145 to
$364 \mathrm{mg} / \mathrm{g} \mathrm{FW}$ between days 3 and 12 of drought stress, while in the drought susceptible cultivar sitosterol levels increased from 137 to $287 \mathrm{mg} / \mathrm{g} \mathrm{FW}$. A similar pattern was observed with regard to campesterol levels, which increased from 103 to $219 \mathrm{mg} / \mathrm{g} \mathrm{FW}$ and from 95 to $154 \mathrm{mg} / \mathrm{g} \mathrm{FW}$ between days 3 and 12 of water deprivation in the drought tolerant and drought susceptible cultivars, respectively. Furthermore, an approximately twofold increase in the activity of HMG-CoA reductase (HMGR), a key limiting enzyme in the MVA pathway, was observed. A significant boost in the content of steryl esters (which constitute up to half of the total sterol accumulated pool), in a manner proportionate to the duration of water deprivation, was noticed, particularly in the drought tolerant cultivar. Taken together, these results indicated a significant increase in the content of sterols and their esters in plants exposed to water deprivation, which further implied that these compounds might play an important role in tolerance to drought stress by reinforcing the cell membranes. It would appear that the greater drought tolerance exhibited by the $\mathrm{N} 22$ rice cultivar may be due to its superior ability to accumulate sterols and their esters in comparison to the drought susceptible cultivar (Kumar et al. 2015).

In a subsequent study, the expression of HMGR and PSAT (phospholipid:sterol acyltransferase) genes was investigated in drought sensitive and drought tolerant rice cultivars under conditions of water deficit (Kumar et al. 2018). PSAT is involved in the conversion of sterols into steryl esters, thereby playing an important role in maintaining membrane homeostasis in response to drought stress. An increase in expression of both genes was observed, which was proportional to the level of severity (duration) of water deprivation. A threefold increase in the expression of HMGR transcript was observed between days 3 and 12 of drought stress in the drought tolerant cultivar, whereas in the drought sensitive cultivar only a twofold increase was observed. Simultaneously, PSAT gene expression exhibited a twofold increase in both the drought tolerant and the drought sensitive cultivars. Thus, this study demonstrated that the changes in sterol and steryl ester levels was accompanied by stimulation of respective gene expression in rice plants exposed to water deficit stress (Kumar et al. 2018).

The enzymes modifying sterol structures, including sterol desaturases and sterol acyltransferases, seem to be particularly involved in drought tolerance in plants. 
FvC5SD is a gene encoding a type of C-5 sterol desaturase isolated from the edible fungus Flammulina velutipes. It has been reported that FvC5SD overexpression in transgenic tomatoes (L. esculentum) leads to enhanced drought tolerance and pathogen resistance. FvC5SD is involved in ergosterol biosynthesis and the nutritional value of transgenic tomato fruits was improved due to increased polyunsaturated fatty acid (PUFA) level. However, no differences were observed in the levels of phytosterols and brassinosteroids between transgenic and wild type plants (Kamthan et al. 2012). In a study involving genetically modified, drought tolerant soybean Glycine max, transgenic plants were generated by insertion of FvC5SD gene by Agrobacterium-mediated transformation and these exhibited enhanced tolerance to dehydration and drought in comparison to wild type plants. In transgenic plants, diminished accumulation of ROS levels was also observed (Zhang et al. 2019). Unfortunately, in this study the sterol content was not determined.

The observed effects of drought stress on the content of sterols and their conjugated forms, particularly esters, in rice cultivars are shown in Table 3 . It would indeed appear that, as glycosylated forms of esters seem to be particularly involved in plant response to cold stress and cold acclimation, SEs may be crucial to survival during water deficit by strengthening the membranes in plant cells. Acylation of sterols is considered an important process in maintaining homeostasis of membrane lipids (Valitova et al. 2016). SEs can be found in lipid bodies in the cytoplasm of plant cells and they are present in substantial amounts in seeds, where they form a storage pool of sterols. Elevation of SE levels during senescence and aging has been well documented and it is considered to be a mechanism for reclaiming membrane lipids. Drought stress is linked with the metabolism of membrane lipids and the associated increase in SE levels seems to be involved in maintaining the integrity of plasma membrane during water deficit (Kumar et al. 2018).

\section{Conclusions}

Sterols are integral components of the membrane lipid bilayer in plants, where they regulate membrane fluidity and thereby influence its structure, properties and functions. Plant membranes are affected by various environmental conditions and sterols play a prominent role in plant response to abiotic stress. Diversity of sterols and their conjugated forms may allow sessile plants to adapt to environmental stress conditions.

Findings from studies presented in this review demonstrate that such abiotic stress factors as cold, drought and UV radiation have an inarguable impact on the biosynthesis and accumulation of various forms of sterols in plant tissues. Some reports correlate changes in the sterol profile, including the ratio of certain compounds (such as 24-methyl to ethyl sterols and sitosterol to stigmasterol, as well as the relative proportions of the conjugated sterols ASGs, SGs and

Table 3 Changes in sterol content in two rice cultivars, drought-tolerant and drought-sensitive, exposed to water deficit stress

\begin{tabular}{|c|c|c|c|c|}
\hline Plant & $\begin{array}{l}\text { Main sterol } \\
\text { profile }\end{array}$ & Stress factor & Effect & References \\
\hline $\begin{array}{l}\text { Rice Oryza } \\
\text { sativa; } \\
\text { drought- } \\
\text { tolerant } \\
\text { cultivar N22 }\end{array}$ & $\begin{array}{l}\text { Sitosterol, } \\
\text { campesterol, } \\
\text { stigmasterol }\end{array}$ & $\begin{array}{l}3,6,9 \text { or } 12 \\
\text { days of water } \\
\text { deficit }\end{array}$ & $\begin{array}{l}\text { Between days } 3 \text { and } 12 \text { of drough stress: twofold increase of } \\
\text { total sterol content (free sterol content increased from } 306 \\
\text { to } 758 \mathrm{mg} / \mathrm{g} \mathrm{FW} \text {, SE content from } 153 \text { to } 364 \mathrm{mg} / \mathrm{g} \mathrm{FW} \text {, the } \\
\text { catalytic activity of HMGR from } 0.55 \text { to } 0.85 \mathrm{mmol} / \mathrm{min} \text { ); } \\
\text { threefold and twofold increase in the expression of HMGR } \\
\text { and PSAT transcripts, respectively }\end{array}$ & $\begin{array}{l}\text { Kumar et al. } \\
\quad(2015,2018)\end{array}$ \\
\hline $\begin{array}{l}\text { Rice Oryza } \\
\text { sativa; } \\
\text { drought- } \\
\text { sensitive } \\
\text { cultivar } \\
\text { IR64 }\end{array}$ & $\begin{array}{l}\text { Sitosterol, } \\
\text { campesterol, } \\
\text { stigmasterol }\end{array}$ & $\begin{array}{l}3,6,9 \text { or } 12 \\
\text { days of water } \\
\text { deficit }\end{array}$ & $\begin{array}{l}\text { Between days } 3 \text { and } 12 \text { of drough stress: twofold increase of } \\
\text { total sterol content (free sterol content increased from } 245 \\
\text { to } 555 \mathrm{mg} / \mathrm{g} \mathrm{FW} \text {, SE content from } 131 \text { to } 283 \mathrm{mg} / \mathrm{g} \mathrm{FW} \text {; the } \\
\text { catalytic activity of HMGR from } 0.31 \text { to } 0.66 \mathrm{mmol} / \mathrm{min} \text { ); } \\
\text { twofold increase in the expression of both HMGR and } \\
\text { PSAT transcripts }\end{array}$ & $\begin{array}{l}\text { Kumar et al. } \\
\quad(2015,2018)\end{array}$ \\
\hline
\end{tabular}


SEs), with specific responses to different types of stress. However, sometimes it can be difficult to unambigously establish whether the increase or decrease in certain sterol forms is directly related to mechanisms of stress response, or merely a secondary product of disturbance or injury exerted by stress factor (Ferrer et al. 2017). Moreover, the pattern of changes observed in these studies cannot be regarded as universal and generalizing to all plants, since some species may have distinct adaptations to environmental conditions and their response to certain stress factors might not depend exclusively on modifications of sterol content in membranes, as was demonstrated in case of olive trees exposed to UV-B radiation stress (Dias et al. 2018).

A further limitation of the research approach utilized in the studies presented in this review is that they were each performed under a single stress factor. Plants are usually exposed to several types of abiotic stress in their natural environment or under field conditions. A recent study involving barley (Hordeum vulgare) showed that a combination of abiotic stressors significantly increased the sterol content, however, it also demonstrated discrepancies between the effect exerted in barley leaves exposed to multiple stressors, particularly for simultaneous drought and heat, and the effects exerted by a single factor (Kuczyńska et al. 2019). Therefore, the investigation on the effects of combinations of abiotic stressors should be considered in the future studies regarding the role of sterols in plant response to environmental cues, which present a major challenge to the contemporary agriculture and food industries as a result of global climate changes.

Open Access This article is licensed under a Creative Commons Attribution 4.0 International License, which permits use, sharing, adaptation, distribution and reproduction in any medium or format, as long as you give appropriate credit to the original author(s) and the source, provide a link to the Creative Commons licence, and indicate if changes were made. The images or other third party material in this article are included in the article's Creative Commons licence, unless indicated otherwise in a credit line to the material. If material is not included in the article's Creative Commons licence and your intended use is not permitted by statutory regulation or exceeds the permitted use, you will need to obtain permission directly from the copyright holder. To view a copy of this licence, visit http://creativecommons.org/licenses/by/4.0/.

\section{References}

Aboobucker SI, Suza WP (2019) Why do plants converts sitosterol to stigmasterol? Front Plant Sci 10:354. https:// doi.org/10.3389/fpls.2019.00354

Ahmed F, Schenk PM (2017) UV-C radiation increases sterol production in the microalga Pavlova lutheri. Phytochemistry 139:25-32. https://doi.org/10.1016/j.phytochem. 2017.04.002

Barrero-Gil J, Salinas J (2013) Post-translational regulation of cold acclimation response. Plant Sci 205:48-54. https:// doi.org/10.1016/j.plantsci.2013.01.008

Barrero-Sicilia C, Silvestre S, Haslam RP et al (2017) Lipid remodelling: unravelling the response to cold stress in Arabidopsis and its extremophile relative Eutrema salsugineum. Plant Sci 263:194-200. https://doi.org/10.1016/ j.plantsci.2017.07.017

Benveniste P (2004) Biosynthesis and accumulation of sterols. Annu Rev Plant Biol 55:429-457. https://doi.org/10.1146/ annurev.arplant.55.031903.141616

Bohn M, Lüthje S, Sperling P et al (2007) Plasma membrane lipid alterations induced by cold acclimation and abscisic acid treatment of winter wheat seedlings differing in frost resistance. J Plant Physiol 164:146-156. https://doi.org/10. 1016/j.jplph.2005.12.008

Bouvier-Navé P, Berna A, Noiriel A et al (2010) Involvement of the phospholipid sterol acyltransferase 1 in plant sterol homeostasis and leaf senescence. Plant Physiol 152:107-119. https://doi.org/10.1104/pp.109.145672

Brosché M, Strid § (2003) Molecular events following perception of ultraviolet-B radiation by plants. Physiol Plant 117:1-10. https://doi.org/10.1034/j.1399-3054.2003. 1170101

Chen M, Thelen JJ (2013) ACYL-LIPID DESATURASE2 is required for chilling and freezing tolerance in Arabidopsis. Plant Cell 25:1430-1444. https://doi.org/10.1105/tpc.113. 111179

Clouse SD (2002) Arabidopsis mutants reveal multiple roles for sterols in plant development. Plant Cell 14:1995-2000. https://doi.org/10.1105/tpc. 140930

Darnet S, Schaller H (2019) Metabolism and biological activities of 4-methyl-sterols. Molecules 24:451. https://doi.org/ 10.3390/molecules 24030451

Degenkolbe T, Giavalisco P, Zuther E et al (2012) Differential remodeling of the lipidome during cold acclimation in natural accessions of Arabidopsis thaliana. Plant $\mathrm{J}$ 72:972-982. https://doi.org/10.1111/tpj.12007

Dias MC, Pinto DC, CorreiaC et al (2018) UV-B radiation modulates physiology and lipophilic metabolite profile in Olea europaea. J Plant Physiol 222:39-50. https://doi.org/ 10.1016/j.jplph.2018.01.004

Dufourc EJ (2008) The role of phytosterols in plant adaptation to temperature. Plant Signal Behav 3:133-134. https://doi. org/10.4161/psb.3.2.5051

Ferrer A, Altabella T, Arró M et al (2017) Emerging roles for conjugated sterols in plants. Prog Lipid Res 67:27-37. https://doi.org/10.1016/j.plipres.2017.06.002

Gil M, Pontin M, Berli F et al (2012) Metabolism of terpenes in the response of grape (Vitis vinifera L.) leaf tissues to UV- 
B radiation. Phytochemistry 77:89-98. https://doi.org/10. 1016/j.phytochem.2011.12.011

Grosjean K, Mongrand S, Beney L et al (2015) Differentialeffect of plant lipids on membraneorganization: specificities of phytosphingolipids and phytosterols. J BiolChe 290:5810-5825. https://doi.org/10.1074/jbc.M114.598805

Hartmann MA (1998) Plant sterols and the membrane environment. Trends Plant Sci 3:170-175. https://doi.org/10. 1016/S1360-1385(98)01233-3

Hollósy F (2002) Effects of ultraviolet radiation on plant cells. Micron 33:179-197. https://doi.org/10.1016/S09684328(01)00011-7

Kamthan A, Kamthan M, Azam M et al (2012) Expression of a fungal sterol desaturase improves tomato drought tolerance, pathogen resistance and nutritional quality. Sci Rep 2:951. https://doi.org/10.1038/srep00951

Kuczyńska A, Cardenia V, Orodowicz P et al (2019) Effects of multipleabioticstresses on lipids and sterols profile in barleyleaves (Hordeumvulgare L.). Plant Physiol Biochem 141:215-224. https://doi.org/10.1016/j.plaphy.2019.05. 033

Kumar MS, Ali K, Dahuja A et al (2015) Role of phytosterols in drought stress tolerance in rice. Plant Physiol Biochem 96:83-89. https://doi.org/10.1016/j.plaphy.2015.07.014

Kumar MS, Mawlong I, Ali K et al (2018) Regulation of phytosterol biosynthetic pathway during drought stress in rice. Plant Physiol Biochem 129:11-20. https://doi.org/10.1016/ j.plaphy.2018.05.019

Lake JA, Field KJ, Davey MP et al (2009) Metabolomic and physiological responses reveal multi-phasic acclimation of Arabidopsis thaliana to chronic UV radiation. Plant Cell Environ 32:1377-1389. https://doi.org/10.1111/j.13653040.2009.02005.x

Lara JA, Burciaga-Monge A, Chávez A et al (2018) Identification and characterization of sterol acyltransferases responsible for steryl ester biosynthesis in tomato. Front Plant Sci 9:588. https://doi.org/10.3389/fpls.2018.00588

Li J, Han X, Wang X (2018) The response of Achyranthesbidentata Blume to short-term UB-B exposure. Russ J Plant Physiol 66:160-170. https://doi.org/10.1134/ S1021443719010096

Mandak E, Nyström L (2012) Sterylferulates, bioactive compounds in cereal grains. Lipid Technol 24:80-82. https:// doi.org/10.1002/lite.201200179

Matus JT (2016) Transcriptomic and metabolomic networks in the grape berry illustrate that it takes more than flavonoids to fight against ultraviolet radiation. Front Plant Sci 7:1337. https://doi.org/10.3389/fpls.2016.01337

Mishra MK, Singh G, Tiwari S et al (2015) Characterization of Arabidopsis sterol glycosyltransferase TTG15/UGT80B1 role during freeze and heat stress. Plant Signal Behav 10:e1075682. https://doi.org/10.1080/15592324.2015. 1075682

Moreau RA, Whitaker BD, Hicks KB (2002) Phytosterols, phytostanols, and their conjugates in foods: structural diversity, quantitative analysis, and health-promoting uses. Prog Lipid Res 41:457-500. https://doi.org/10.1016/ S0163-7827(02)00006-1

Moses T, Pollier J, Thevelein JM et al (2013) Bioengineering of plant (tri) terpenoids: from metabolic engineering of plants to syntheticbiologyin vivo and in vitro. New Phytol 200:27-43. https://doi.org/10.1111/nph.12325

Örvar BL, Sangwan V, Omann F et al (2000) Early steps in coldsensing by plant cells: the role of actin cytoskeleton and membrane fluidity. Plant J 23:785-794. https://doi.org/ 10.1046/j.1365-313x.2000.00845.x

Palta JP, Whitaker BD, Weiss LS (1993) Plasma membrane lipids associated with genetic variability in freezing tolerance and cold acclimation of Solanum species. Plant physiol 103:793-803. https://doi.org/10.1104/pp.103.3. 793

Raksha BR, Siva R, Vino S et al (2016) Spatio-varietal differences in stigmasterol biosynthesis in tomato and overexpression of a sterol desaturase gene for enhanced stigmasterol production. In Vitro Cell Dev Biol Plant 52:571-579. https://doi.org/10.1007/s11627-016-9794-1

Robson TM, Klem K, Urban O et al (2015) Re-interpreting plant morphological responses to UV-B radiation. Plant Cell Environ 38:856-866. https://doi.org/10.1111/pce.12374

Schaeffer A, Bronner R, Benveniste P et al (2001) The ratio of campesterol to sitosterol that modulates growth in Arabidopsis is controlled by STEROL METHYLTRANSFERASE 2; 1. Plant J 25:605-615. https://doi.org/ 10.1046/j.1365-313x.2001.00994.x

Schaller H (2004) New aspects of sterol biosynthesis in growth and development of higher plants. Plant Physiol Biochem 42:465-476. https://doi.org/10.1016/j.plaphy.2004.05.012

Takahashi D, Imai H, Kawamura Y et al (2016) Lipid profiles of detergent resistant fractions of the plasma membrane in oat and rye in association with cold acclimation and freezing tolerance. Cryobiology 72:123-134. https://doi.org/10. 1016/j.cryobiol.2016.02.003

Takshak S, Agrawal SB (2015) Alterations in metabolite profile and free radical scavenging activities of Withaniasomnifera leaf and root extracts under supplemental ultraviolet-B radiation. Acta Physiol Plant 37:260. https://doi.org/ 10.1007/s11738-015-2014-5

Tapken W, Murphy AS (2015) Membrane nanodomains in plants: capturing form, function, and movement. J Exp Bot 66:1573-1586. https://doi.org/10.1093/jxb/erv054

Thomashow MF (1999) Plant cold acclimation: freezing tolerance genes and regulatory mechanisms. Annu Rev Plant Biol 50:571-599. https://doi.org/10.1146/annurev.arplant. 50.1.571

Valitova JN, Sulkarnayeva AG, Minibayeva FV (2016) Plant sterols: diversity, biosynthesis, and physiological functions. Biochem (Moscow) 81:819-834. https://doi.org/10. 1134/S0006297916080046

Valitova J, Renkova A, Mukhitova F et al (2019) Membranesterols and genes of sterol biosynthesisareinvolved in the response of Triticumaestivumseedlings to coldstress. Plant Physiol Biochem 142:452-459. https://doi.org/10.1016/j. plaphy.2019.07.026

Villette C, Berna A, Compagnon V et al (2015) Plant sterol diversity in pollen from angiosperms. Lipids 50:749-760. https://doi.org/10.1007/s11745-015-4008-x

Whitaker BD (1993) Lipid changes in microsomes and crude plastid fractions during storage of tomato frutis at chilling and nonchilling temperatures. Phytochemistry 32:265-271. https://doi.org/10.1016/S00319422(00)94979-3 
Zhang L, Li T, Wang Y et al (2019) FvC5SD overexpression enhances drought tolerance in soybean by reactive oxygen species scavenging and modulating stress-responsive gene expression. Plant Cell Rep 38:1039-1051. https://doi.org/ 10.1007/s00299-019-02424-y

Zlatev ZS, Lidon FJ, Kaimakanova M (2012) Plant physiological responses to UV-B radiation. Emir J Food Agric. https://doi.org/10.9755/ejfa.v24i6.14669
Publisher's Note Springer Nature remains neutral with regard to jurisdictional claims in published maps and institutional affiliations. 